\title{
DESENHO E UNIVERSALIDADE. NOTAS SOBRE OS DESENHOS DE JÚLIO POMAR NA AMAZÓNIA, 1988
}

\author{
DRAWING AND UNIVERSALITY. NOTES ABOUT JÚLIO POMAR'S
}

DRAWINGS IN AMAZONIA, 1988

\section{Shakil Y. Rahim \\ Universidade de Lisboa}

\section{Resumo}

Os desenhos de Júlio Pomar, no Xingu, são registos das estruturas de movimento do corpo, da luz e do espaço, na representação dos rituais e práticas locais. Na Amazónia, o desenhador encontra o contraste entre a luz-visibilidade da aldeia e a luz-invisibilidade da floresta, que organiza as relações de claro-escuro, naturezacultura e estrutura-entropia. O traço é gestual e desassossegado, com linhas e densidades gráficas que investigam a anatomia, o volume, a sombra, a perspetiva, a escala e a proporção, do nu individual e coletivo. Ritmos, composições e tensões visuais, com desenhos revisitados e acumulações entre observação e memórias. Com o desenho dos resíduos do movimento como estruturas da perceção e aceleração visual, Pomar sintetiza o 'modelo reduzido' de Lévi-Strauss ao comprimir a transferência gráfica com a inteligência da atenção visual. Com esta interpretação temporal encontrase com a universalidade da experiência humana.

\section{Palavras-chave:}

Desenho; Observação; Movimento; Gestualidade.

\section{O TERRITÓRIO, A PAISAGEM E O CENÁRIO}

Júlio Pomar (1926-2018), pintor ${ }^{1}$ do modernismo português², realizou em 1988 uma visita esporádica à Amazónia (região do Alto Xingu), no contexto que o próprio explica:

Eu vinha por escassos dias, parasitei o lugar durante dois meses. (...) O meu amigo Roberto Fonseca, jovem empresário brasileiro, num encontro em Lisboa, no mês de Junho do ano passado, desafiara-me aproveitar o acampamento instalado numa clareira aberta em plena selva do Xingu, na bacia amazónica, base logística das filmagens de QUARUP, o filme de Ruy Guerra do

\section{Abstract}

Júlio Pomar's drawings, in the Xingu, are traces of the movement structures of the body, light and space, on local rituals and practices representation. In the Amazon, the drawer finds the contrast between the light-visibility of the village and the light-invisibility of the forest, which organizes the relations of light-dark, nature-culture and structure-entropy. The stroke is gestural and restless, with lines and graphical densities that investigate anatomy, volume, shadow, perspective, scale, and proportion, of individual and collective nude. Rhythms, compositions, and visual tensions, with revisited drawings and accumulations between observation and memories. With the drawing of movement residues as structures of perception and visual acceleration, Pomar synthesizes LéviStrauss' 'reduced model' by compressing the graphic transference with the intelligence of visual attention. With this time interpretation he meets with the universality of human experience.

Keywords:

Drawing; Observation; Motion; Gesturally.

qual ele havia entusiasticamente assegurado a produção (POMAR, 2014, p. 157).

Este é um território estranho, primitivo ${ }^{3}$ e imprevisível, mas também de beleza, surpresa e novidade: “No acampamento, Hotel de mil estrelas, como Roberto Ihe chamava (...) acomodaram-me o mais belo atelier que jamais terei" (POMAR, 2014, p. 158). Pomar encontra neste atelier ao ar livre, e na tenda em que se aloja durante o filme Kuarup ${ }^{4}$, a possibilidade de observar, desenhar e recriar os diferentes rituais, cerimónias e festas que fazem parte da vida e da morte dos autóctones. 
O Xingu serviu de paisagem, de cenário de produção e de modelo de registo, num estar dentro, mas sempre fora, possível na distância permitida, sugerida, controlada ou fantasiada.

Mas o Xingu era já por essa altura uma zona protegida. Data dos anos 60 a homologação do Parque Indígena do Xingu, e foi a primeira terra indígena delimitada e classificada, numa área atual de aproximadamente 30.000 quilómetros quadrados (FREITAS; FREITAS, 2003, p. 6), onde se encontram vários grupos étnicos e linguísticos. Está localizado no estado do Mato Grosso, na transição entre o Planalto Central e a Floresta da Amazónia: uma zona plana intercetada pelo rio que lhe dá o nome e pelos seus afluentes.

A proteção da identidade cultural e diversidade indígena surgiu na sequência do movimento Marcha para o Oeste, planeado pelo governo de Getúlio Vargas, no sentido de ocupar o Brasil Central e criar um país novo (CAPELATO, 2017, p. 123) e integrado. O quadro estratégico de combate aos desequilíbrios geográficos e assimetrias económicas regionais justificou o impulso expansionista do Estado. "A Amazônia era um mundo remoto, e o Brasil Central, como dizia o jornalista Jorge Ferreira, parecia 'mais distante que a África'" (BÔAS; BÔAS, 2012, p. 34).

A urgência de preencher os vazios demográficos criou a necessidade de circunscrever as populações indígenas já estabelecidas. Nos anos 40 do século $\mathrm{XX}$, a Expedição Roncador-Xingu, sob a chefia dos irmãos Villas Bôas, tentou promover o equilíbrio, a continuidade e o contato, num modelo protecionista de integração e "reprodução simbólica e material das comunidades" (FILHO, 2006, p. 47). Com isso pretendia preservar a qualidade das práticas sociais e de todo o ecossistema natural e cultural.

\section{A ALDEIA, o CíRCULO E A LUZ}

A estadia de Pomar ocorreu numa aldeia lawlapiti, de língua aruaque, durante aproximadamente dois meses. A geometria ordenada da implantação da aldeia impressionou Pomar: uma claraboia em contraste com a densidade da floresta. Sobre esse deslumbramento escreve:

À minha chegada à aldeia lawlapiti deslumbroume o rigor do seu desenho num enorme círculo, sobre o qual parecia assentar a esmagadora abóbada do céu, contrariamente ao que se sente na aproximação da floresta, em que vida e morte estão presentes uma ao pé da outra, e a luz desparece pela selvagem progressão da natureza, pela sua capacidade de resistir à ordenação humana (POMAR, 2017b, p. 3).

Nesta passagem Pomar assinala diversas estruturas: i) o círculo como ordem ancestral, visual e vivencial, ii) a abóbada do céu como cobertura da aldeia que se torna o arquétipo de uma casa para todos, iii) a organização da luz-visibilidade da aldeia e as fraturas da luzinvisibilidade da floresta.

O círculo como ordem visual é uma centralidade cósmica, que representa expansão e movimento. Uma totalidade simétrica e equidistante que significa útero e proteção, num perímetro fechado e controlado. Como refere Arnheim em $O$ Poder do Centro:

Um grupo social, seja ele a família, uma associação, uma nação, ou mesmo a humanidade como um todo, na sua relação com a natureza, mantém a centricidade como forte componente da sua perspetiva e da sua motivação (ARNHEIM, 2001, p. 18-19).

A circularidade da forma, do espaço e do tempo, sem princípio nem fim, encontram na abóbada do céu um teto de conexão celestial para a casa comunitária, e no diâmetro do agrupamento uma forte noção de horizontalidade (GHEERBRANT, 1997, p. 75). Unidade e harmonia da sintaxe visual, que organiza o espaço, o calor e a luz-visibilidade da aldeia em contraste com a desordem, densidade e opacidade da luz-invisibilidade da floresta. Estas duas Luzes compõem a paisagem e as relações entre claro e escuro, natureza e cultura, estrutura e entropia, autonomia e ritual, realidade e mito.

Nesta paisagem fenomenológica, o desenho de Pomar não é político, nem científico ou sociológico; tão pouco é exclusivamente etnográfico ${ }^{5}$ como se poderia prever de um olhar estrangeiro que produz um desenho descritivo e funcional. Não é também a interpretação de um desenho de reportagem ${ }^{6}$, dos hábitos e das exceções de caracter noticioso de um jornalismo de conteúdo turístico, de denuncia ou de guerrilha (EMBURY; MINICHIELLO, 2018, p. 151). Muito menos é uma ilustração, para anexar ao pensamento. Os desenhos do Xingu são resíduos que ficaram do movimento humano, quando este intersecta a luz; aquele momento em que já não é necessário distinguir espaço, corpo, ação e representação. 

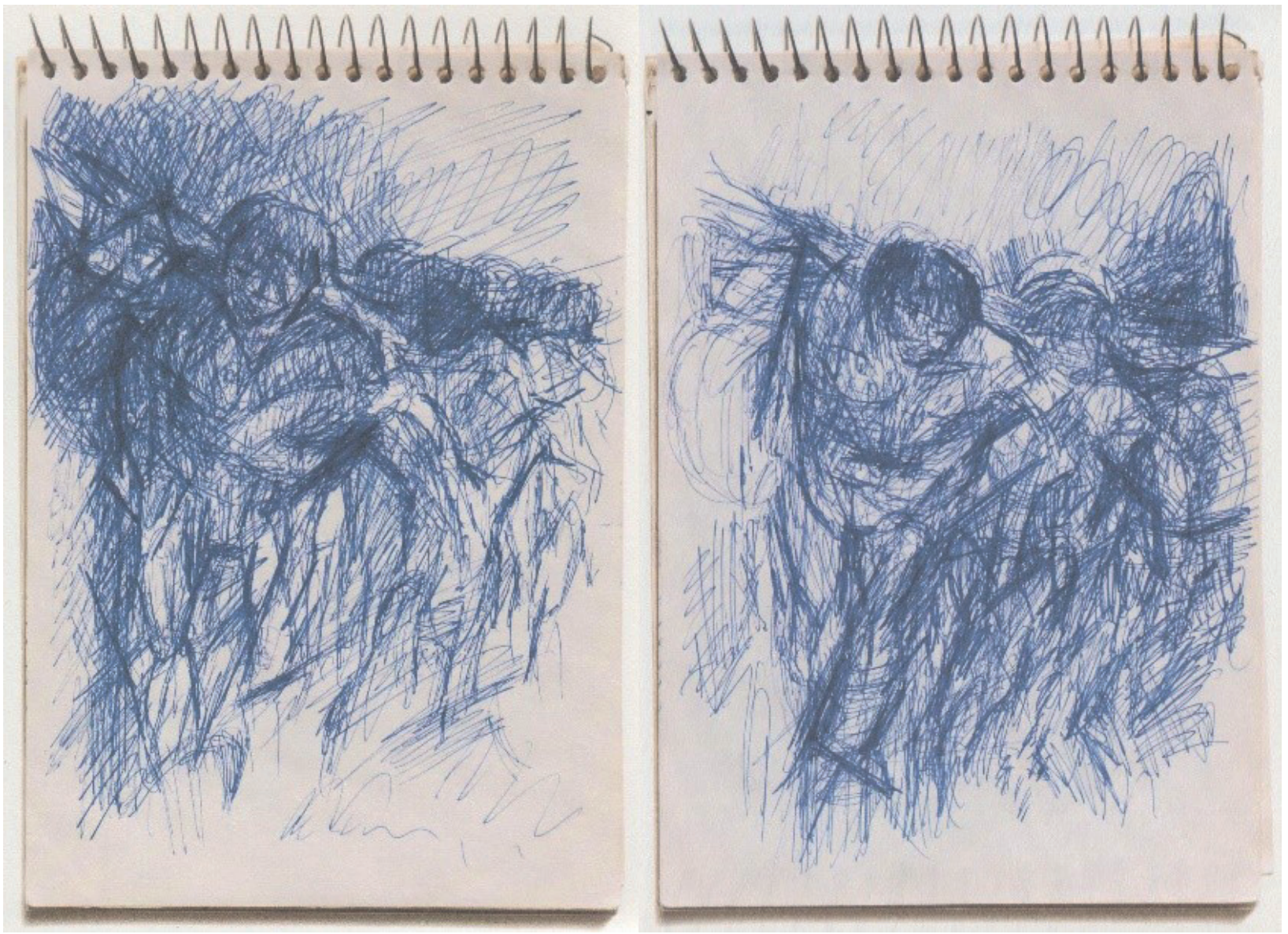

Figura 1 - Júlio Pomar, Desenhos de Kuarup, 1988. Esferográfica sobre papel, 2 páginas, 21 x 14,5 cm. Fonte: Pomar, $2017 a$.

O espaço adquire uma antropologia de distâncias entre o público e privado, numa orientação não euclidiana ou não-ordenada por um código cultural comum. Em simultâneo o corpo em si e para si, enquanto medida de liberdade na aceção de Sartre: entre o que se é e o que se deseja ser (BRAUNSTEIN; PÉPIN, 2001, p. 137). Acrescentase ainda aquilo que se pode ser, isto é, o corpo como expressão coletiva e comunitária ou como evidência do nu; na fusão das figuras, poses e anatomias durante o ritmo das atividades.

A ação é a libertação de energia para formalizar os rituais, e permite construir mensagens de grupo, com recurso ao movimento e à abstração pessoal do corpo (LIBBY; SCHAEFFER; EIBACH, 2009). A representação estabiliza a ordem e a hierarquia dessa ação. Por isso, espaço, corpo, ação e representação são desenhados como estruturas de luz e movimento.

\section{O DESENHO, A DENSIDADE E A COMPOSIÇÃO}

O acervo dos desenhos realizados no Xingu pertence à coleção do Atelier Museu Júlio Pomar, com mais de dez cadernos realizados in situ, e parte deles foram mostrados pela primeira vez ao público na exposição Táwapayêra (MATOS, 2017, p. 22). O conjunto organiza-se por alguns temas locais: i) Kuarup - cerimónia de homenagem aos mortos, ii) Huka-Huka - luta corporal masculina, iii) Jakúi - ritual da flauta sagrada, iv) festa do papagaio, v) arquitetura de habitação e espaços naturais, e vi) os Txicão e outros grupos indígenas em cenas e práticas do quotidiano.

Muitos dos desenhos desta viagem foram feitos em cadernos de argolas, em formatos pequenos e retângulos normalizados, mas longe de contornar ou seguir os enquadramentos poligonais das folhas. Pomar parece promover novas formas de visibilidade com intervenção na 'distribuição geral das maneiras de fazer' (RANCIÈRE, 2005, p. 17). Tal como na sua obra pictórica, regista manchas gráficas que crescem com escalas diferentes, altera posições de centroperiferia, como se as folhas fossem um contínuo para múltiplos registos (Huka-Huka), ou uma caixa onde não cabe o campo visual (festa do papagaio).

A cerimónia de homenagem aos mortos ilustres, ou Kuarup, foi registada com a tensão muscular dos homens que carregam o tronco de madeira, que simboliza o morto (Figura 1). Em Pomar, o 


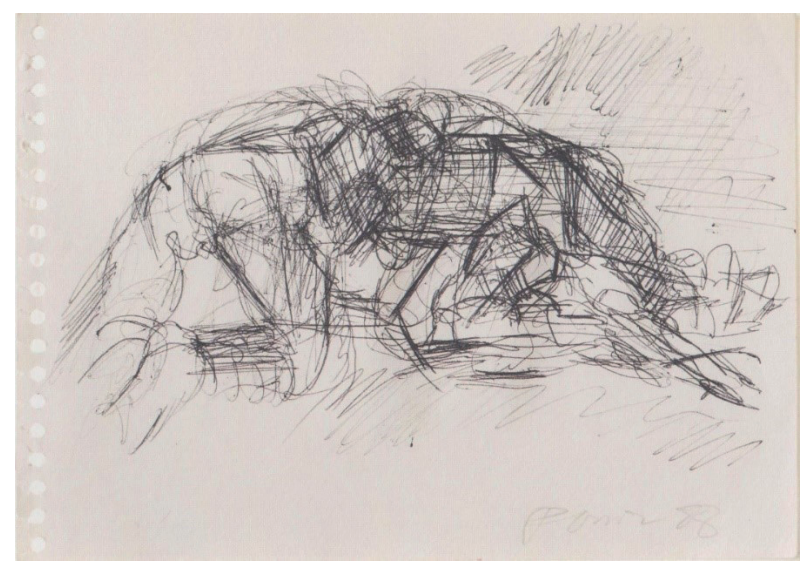

Figura 2 - Júlio Pomar, Desenho de Huka-Huka, 1988. Esferográfica sobre papel, $14,5 \times 20,3 \mathrm{~cm}$. Fonte: Pomar, 2017a.

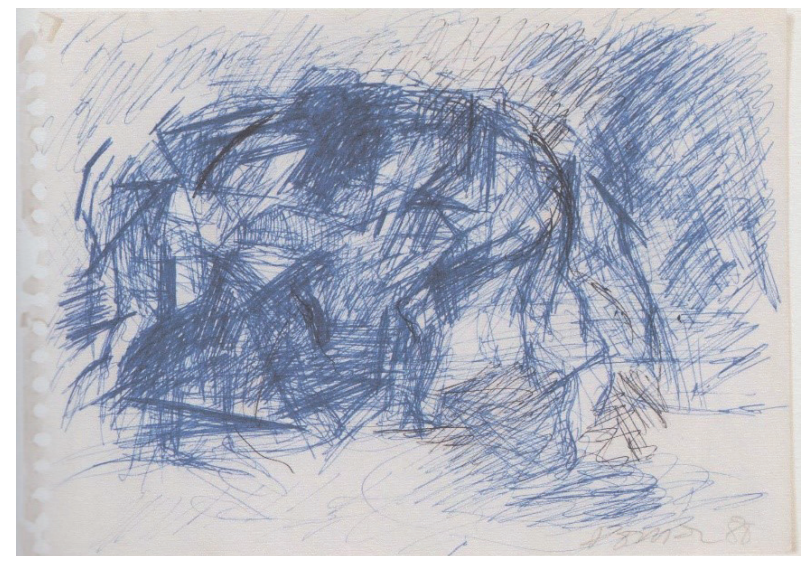

Figura 3 - Júlio Pomar, Desenho de Huka-Huka, 1988. Esferográfica sobre papel, $14,5 \times 20,3 \mathrm{~cm}$. Fonte: Pomar, 2017a.

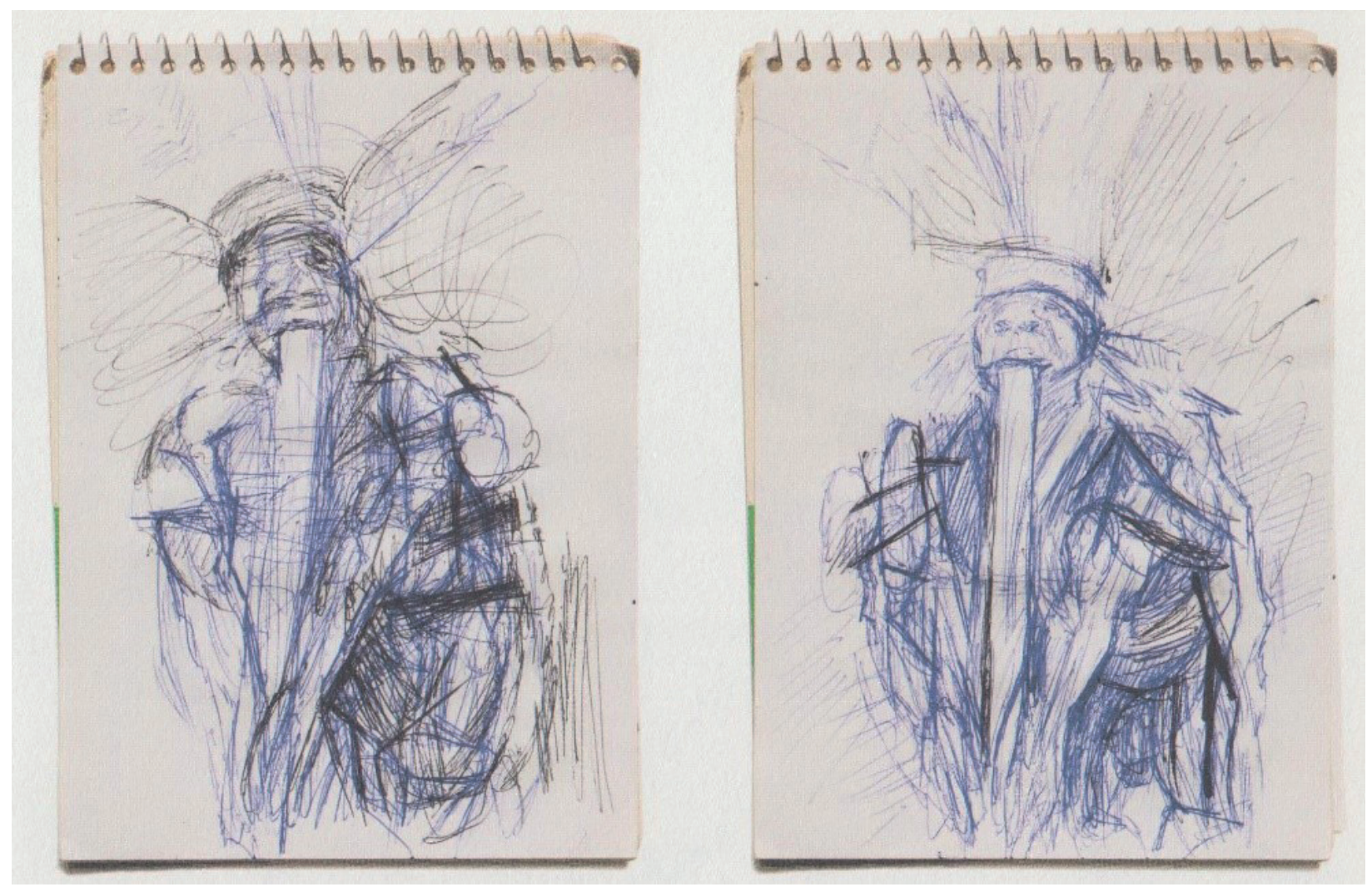

Figura 4 - Júlio Pomar, Desenhos de Jakúi, 1988. Esferográfica sobre papel, 2 páginas, 20,3 x 14,5 cm. Fonte: Pomar, 2017a.

desenho da forma é a do movimento, mas não exclusivamente do movimento descrito, mas do gesto que o inscreve (ROSENDO, 2016, p. 130). Pela força como se organizou a materialização da linha, a marcação facetada do contorno e a sugestão da perspetiva de um ponto de fuga, a tensão de cada corpo distribui-se pelo conjunto e pelo movimento sequencial.

O desenho da luta corporal masculina durante a cerimónia do Kuarup, ou Huka-Huka, segue também esta distribuição de forças físicas e visuais, pela fusão dos corpos de onde resulta uma nova estrutura compositiva, quase em abóbada ou como quadrúpede (Figura 2). Nos desenhos de Kuarup, o pronunciamento poliédrico do contorno e a densidade gráfica desenham a tensão visual (Figura 3). Refere Ana Gonçalves:

Um tipo de luta muito semelhante à greco-romana, em que os homens começam por se saudar, depois envolvem-se numa espécie de abraço, terminando o combate quando um dos homens consegue imobilizar o outro no chão (GONÇALVES, 2017, p. 20). 


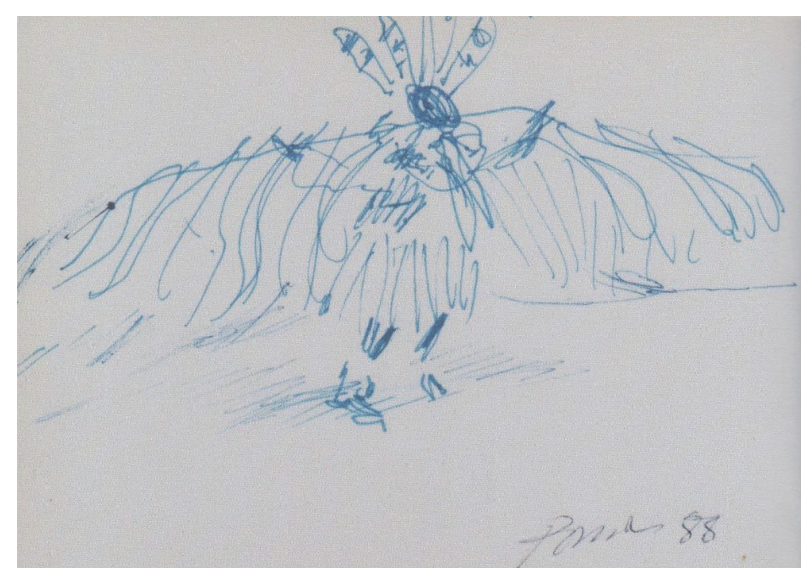

Figura 5 - Júlio Pomar, Desenho da Festa de Papagaio, 1988. Esferográfica sobre papel, 9 x 13 cm. Fonte: Pomar, $2017 a$.

No conjunto dos desenhos do Jakúi, ou ritual da flauta sagrada, mantem-se a mesma estratégia gráfica de estudo da tensão, do movimento e do contorno dos homens, com a verticalidade das flautas e o triângulo dos braços a dominarem a composição (Figura 4). Como refere Paulo Herkenhoff, nalguns dos desenhos do Jakúi as marcas da caneta de feltro conferem estrutura à imagem (GHEERBRANT, 1997, p. 69). São rostos marcados pelo desenho da pressão da boca, em composições com ritmo e plasticidade acústica.

A festa do papagaio é um ritual de dança das aldeias Kamayurá que organiza relações de poder, com ornamentos, vestes e adereços próprios (Figura 5). Os desenhos mantém o padrão de procura dos vestígios do movimento do corpo, dentro de uma perspetiva natural e não-linear, ótica, esférica e sensível (PANOFSKY, 1993, p. 37), intuída por dupla circularidade: a da aldeia e a das asas das vestes (Figura 6).

Sobressai nestes desenhos da festa do papagaio a volumetria das ocas, espaços típicos de habitação coletiva da aldeia, onde a força visual da escala se impõe (Figura 7). De planta oval, normalmente de madeira e cobertura-fachada em palha ou folhas de palmeira, estas estruturas arquitetónicas têm associações antropomórficas, não apresentam janelas nem divisões internas, e os acessos são feitos por porta-buraco (COSTA; MALHANO, 1986, p. 5455). Esta opacidade e continuidade visual/material da arquitetura está presente nos desenhos do Xingu.

Pontualmente surgem desenhos de árvores e de recortes de floresta, e de alguns animais isolados

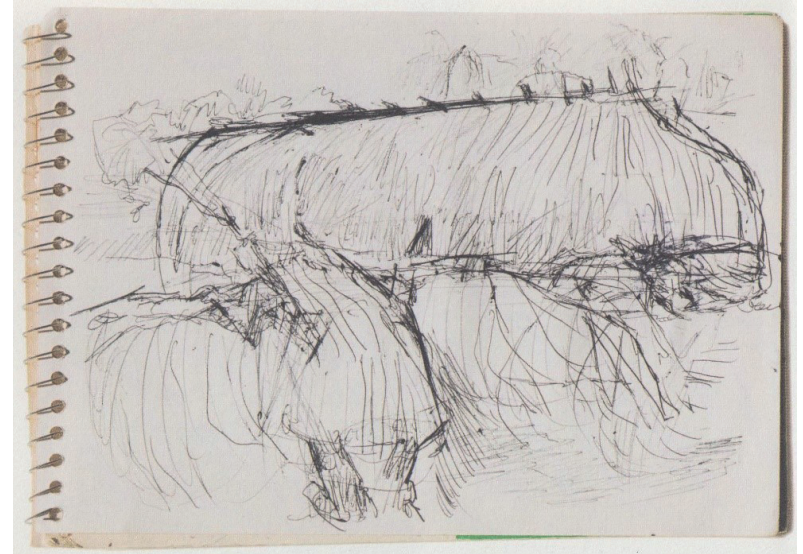

Figura 6 - Júlio Pomar, Desenho da Festa de Papagaio, 1988. Esferográfica sobre papel, 14,5 x 20,3 cm. Fonte: Pomar, 2017 a.

(Figura 8). O espaço natural é consequência do desenho da envolvente. Mas a figura humana é o tema de maior frequência. Os desenhos das práticas quotidianas dos diferentes grupos indígenas (Txicão, Yawalapitis, Kamaiurás) atravessam vários cadernos, com figuras isoladas ou em conjunto, homens e mulheres, adultos e crianças, parados ou em movimento.

"Os desenhos de Pomar exploram a linguagem do corpo, sublinham o potencial expressivo do traço rápido, são comunicantes, indexam e testemunham o primordial da vida da floresta amazónica" (FARO, 2017, p. 195). Mais do que tramas tradicionais com geometria ordenada, Pomar risca em movimentos pendulares e multidirecionais para preencher a profundidade formal e espacial (Kuarup e Txicão). Há desenhos de linha única, mas, no geral, predomina a densidade de riscos.

O uso da densidade gráfica através da sobreposição de linhas tem várias funções nestes desenhos: i) marcação da intensidade da vegetação da floresta, ii) definição do contorno do volume por aproximação, iii) modelação de claro-escuro na produção da profundidade, iv) movimentos dos gestos e da ação, v) massas e forças na construção da figura humana e vi) aceleração gráfica na observação da imagem. Alguns deles carregam um resumo de violência, energia e força, que Sara Antónia Matos resume:

Dos seus emaranhados de linhas, por vezes tão sobrecarregados que preenchem a superfície do papel na totalidade, vemos destacar-se corpos em movimento, os quais ganham espessura, se esbatem entre si e voltam a redefinir-se nos seus 

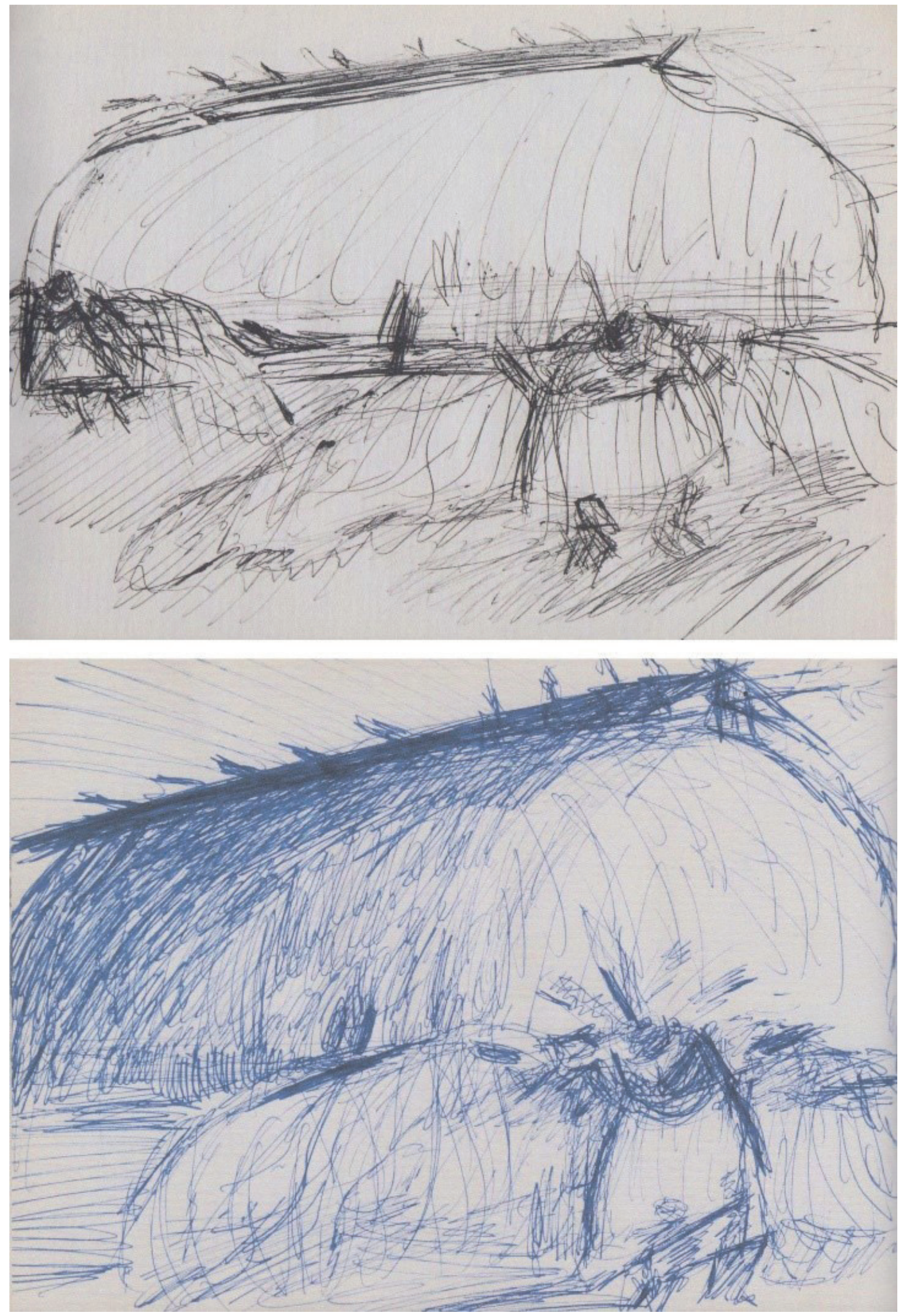

Figura 7 - Júlio Pomar, Desenhos da Festa de Papagaio, 1988. Esferográfica sobre papel, 2 páginas, 14,5 x 20,3 cm. Fonte: Pomar, 2017 a. 


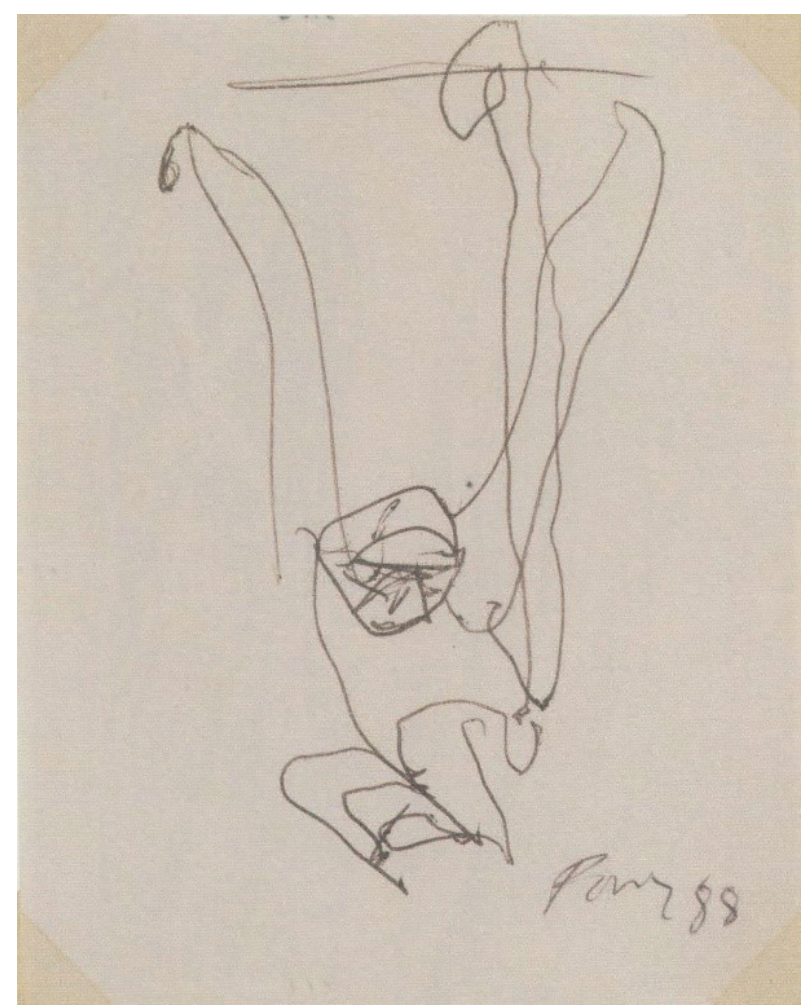

Figura 8 - Júlio Pomar, Desenho de Macaco, 1988. Esferográfica sobre papel, $9,5 \times 7,5 \mathrm{~cm}$. Fonte: Pomar, 2017a.

contornos possantes, como nas lutas de homens, musculados. A densidade pode observar-se também nas representações de ocas (casas), que adquirem volume à custa da sobreposição de linhas, ou ainda de índios empunhando arcos e flechas que se dissimulam e simultaneamente se destacam entre um enredo de riscos representando a vegetação da selva (MATOS, 2017, p. 22).

Os riscadores repetem-se e por vezes sobrepõem-se, entre grafite, esferográfica e marcador, a preto, a azul e por vezes verde ou vermelho (GONÇALVES, 2017, p. 13). O contraste do marcador assinala forças estruturantes da forma, da luz ou do movimento (Jakúi). A monotonia cromática das pontas secas, onde a presença da cor acentua-se pela densidade da linha, sublinha a profundidade de campo e a diferença dos planos de observação. A cinética da mão circunscreve o comprimento e ritmo dos trajetos "da natureza dócil ou perturbante do utensílio" (POMAR, 2014, p. 141), com resistências e interferências no cálculo das escalas, das densidades e do claro-escuro.

Mas habituados aos desenhos de economia linear de Júlio Pomar, estaremos com esta densidade gráfica numa nova compreensão visual? No essencial não. Pomar continua a explorar as estruturas da síntese da perceção, e o desenho mantém o uso de elementos simples e repetidos, ainda que tenha preenchido as áreas. Continuam assim a servir de análise visual para outras produções.

Por exemplo, os desenhos do Xingu serviram de origem projetual à sua pintura (MATOS, 2017, p. 22), tornando-se instrumento para as séries sobre a Amazónia, em produções realizadas no mesmo ano, como o quadro Os Txicão (1988) e Kuarup I/ (1988), ou outras pinturas criadas quase dez anos depois como $O$ banho das crianças no Tuatuari (1997). As cenas de banhistas de Pomar, em alusão a Cézanne e à composição fundida do corpo e da paisagem de Les Grandes Baigneuses, ao que acresce a influência da paleta escura e planificação da forma de Gauguin ou o movimento carnal de Rubens (WOHL, 2004, p. 34), são um retorno à memória e aos desenhos do Xingu, como o próprio pintor refere:

\begin{abstract}
A tela seguiu o seu curso. Trabalhava nela de manhã à noite quando fiz a descoberta, na sacola que no Xingu trazia sempre comigo e na qual guardava todos os meus caderninhos, do último deles onde tinha feito algumas anotações rápidas sobre as minhas Banhistas, algumas tentativas de delineação. Tinha esquecido completamente a própria existência destes rascunhos! (POMAR, 2017a, p. 102).
\end{abstract}

Não são propriamente desenhos preparatórios, mas os usos posteriores flutuam entre necessidades, releituras e memórias, a que Pomar se refere: "não duvido que a memória, máquina mal regulada, o trata (ou maltrata) à sua maneira" (POMAR, 2017a, p. 111). Os desenhos no Xingu adquirem por isso várias funções, entre rascunho, esboço, apontamento, esquema, recuperação, observação e reconstrução. Funções que flutuam entre suportes como refere Moreira:

A noção de suporte é exclusiva das artes plásticas. O poema, o romance, a sinfonia, não dependem de suportes, sendo, nesse sentido, "imateriais".

A dependência de um suporte não constitui no entanto uma limitação. Pelo contrário, poderia considerar-se uma mais-valia, na medida em que a obra pode viajar de suporte sem perder a sua identidade, enriquecendo-se da diversidade de roupagens.

Sem abandonar a fidelidade ao quadro, Júlio Pomar tem sabido viajar por todos os suportes, procurando as necessidades consonâncias com as obras (MOREIRA, 2019, p. 84). 
Estas transferências são também ensaiadas nos atos de desenhar durante a estadia na aldeia, entre observação e memória, a que Pomar chama desenhos revisitados (FARO, 2017, p. 194). Os registos sobrepõem-se por método de acumulação gráfica de linhas, através de vários dias, onde a experiência "do natural" é extrapolada para desenhos reconstrutores.

Segundo sabemos, através de Alexandre Pomar, e do próprio artista, os desenhos são, em geral, feitos no final da tarde, na tenda e já não diante dos modelos - os ameríndios - mas reinterpretando memórias e figuras. Durante o dia, as crianças não o deixavam desenhar sossegado porque estavam sempre a espreitar e a pedir coisas (;) Talvez só os desenhos dos cadernos mais pequenos, com desenhos mais esquemáticos, sejam feitos «do natural». Haverá, então, desenhos que são retomados, e noutros casos parece que se trata mais de recuperar o motivo numa nova folha, em ocasiões ou dias sucessivos (FARO, 2017, p. 194).

\section{O MOVIMENTO, A EXPRESSÃO E A UNIVERSALIDADE}

Os desenhos do Xingu não são registos que apresentam a diferença cultural inerente às práticas locais. Antes procuram o que é universal. Investigam a estrutura do movimento da luz e do corpo transferida para a experiência de observação, num desassossego gestual por dentro do processo: entre a indefinição, o inacabado e a aproximação.

O movimento é então uma categoria estruturante desta produção visual, que questiona a relação entre si próprio e o outro, que não é pessoal nem social, "é um factor permanente e universal da nossa estrutura mais arcaica" (MOREIRA, 2019, p. 82).

0 registo do movimento, num suporte como o desenho, é a virtualidade da sua sugestão. Durante o processo de fixação da imagem a "sugestão de movimento nas manifestações visuais estáticas é mais difícil de conseguir sem que ao mesmo tempo se distorça a realidade" (DONDIS, 2007, p. 80), uma vez que é necessário desenhar a volátil dimensão do tempo nas dimensões formais e espaciais da luz e da geometria. Estas mudam a cada momento.

A geometria é nivelada e o desenho da intensidade da luz do Sol parece invocar o uso da claridade como composição do reflexo, que aparece entre a densidade dos riscos e delimita a força da incidência dos raios solares nas subtrações dos ornamentos

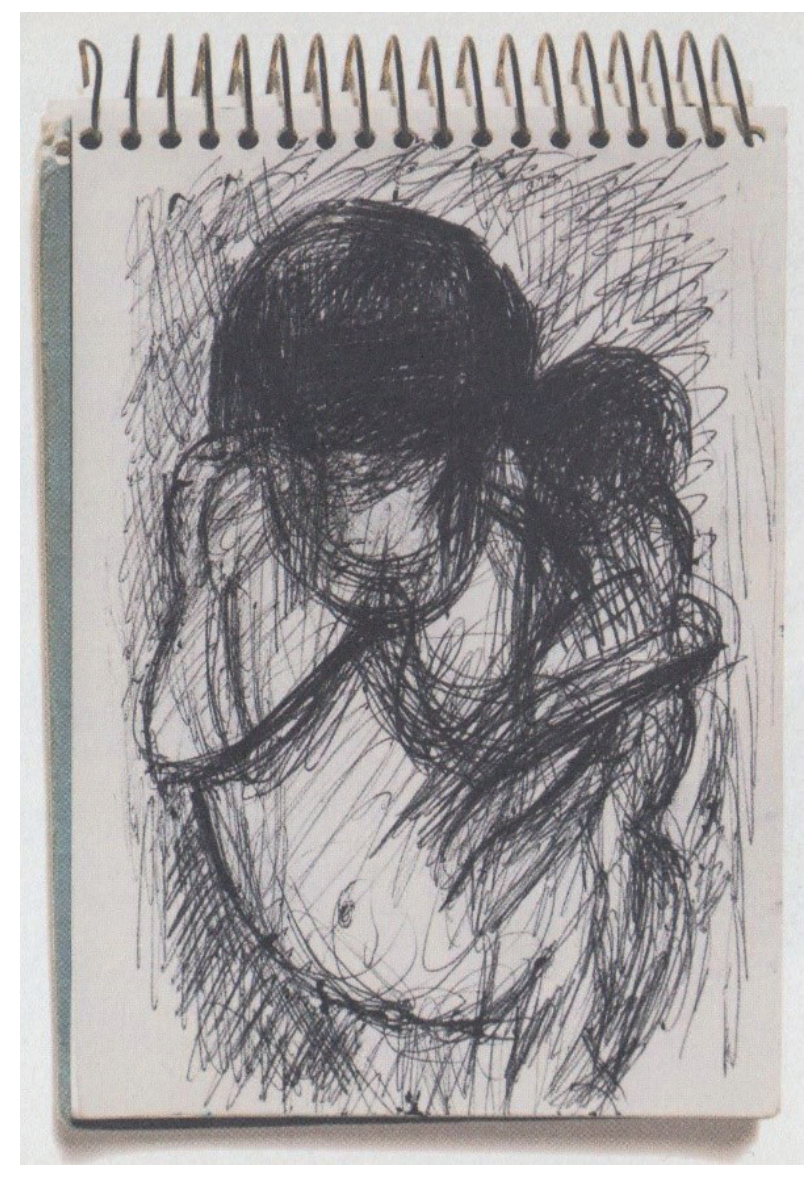

Figura 9 - Júlio Pomar, Desenho de Mulher com Criança, 1988. Esferográfica sobre papel, $13 \times 9$ cm. Fonte: Pomar, 2017a.

cromáticas sobre a pele. "Crus contrastes de cor, de matéria também, ao compasso dos corpos que acabam por se fragmentar num puzzle em cuja lógica os nossos olhos não atinam, meio cegos por um sol que não perdoa" (POMAR, 2014, p. 157).

Opuzzle aque serefereo desenhador sãoas fraturas da luz nos contornos que dividem a superfície corporal e a reorganiza por conjuntos, relações e ritmos visuais não classificados. Os desenhos descrevem movimentos, que reconfiguram a anatomia, a musculatura, as articulações e a pele, por agrupamentos de características gráficas e relações entre conjuntos (figura, volume, contorno, sombra, reflexo, contraste). Como refere Moreira ao citar Da Cegueira dos Pintores ${ }^{8}$, texto do próprio desenhador: estas são 'formas que se tornam outras' (MOREIRA, 2019, p. 82).

São formas de uma 'recomposição derivada' do natural, onde desaparecem os códigos das poses consagradas pela história da arte e se reativam as funções da nudez original. Nos desenhos do Xingu, 


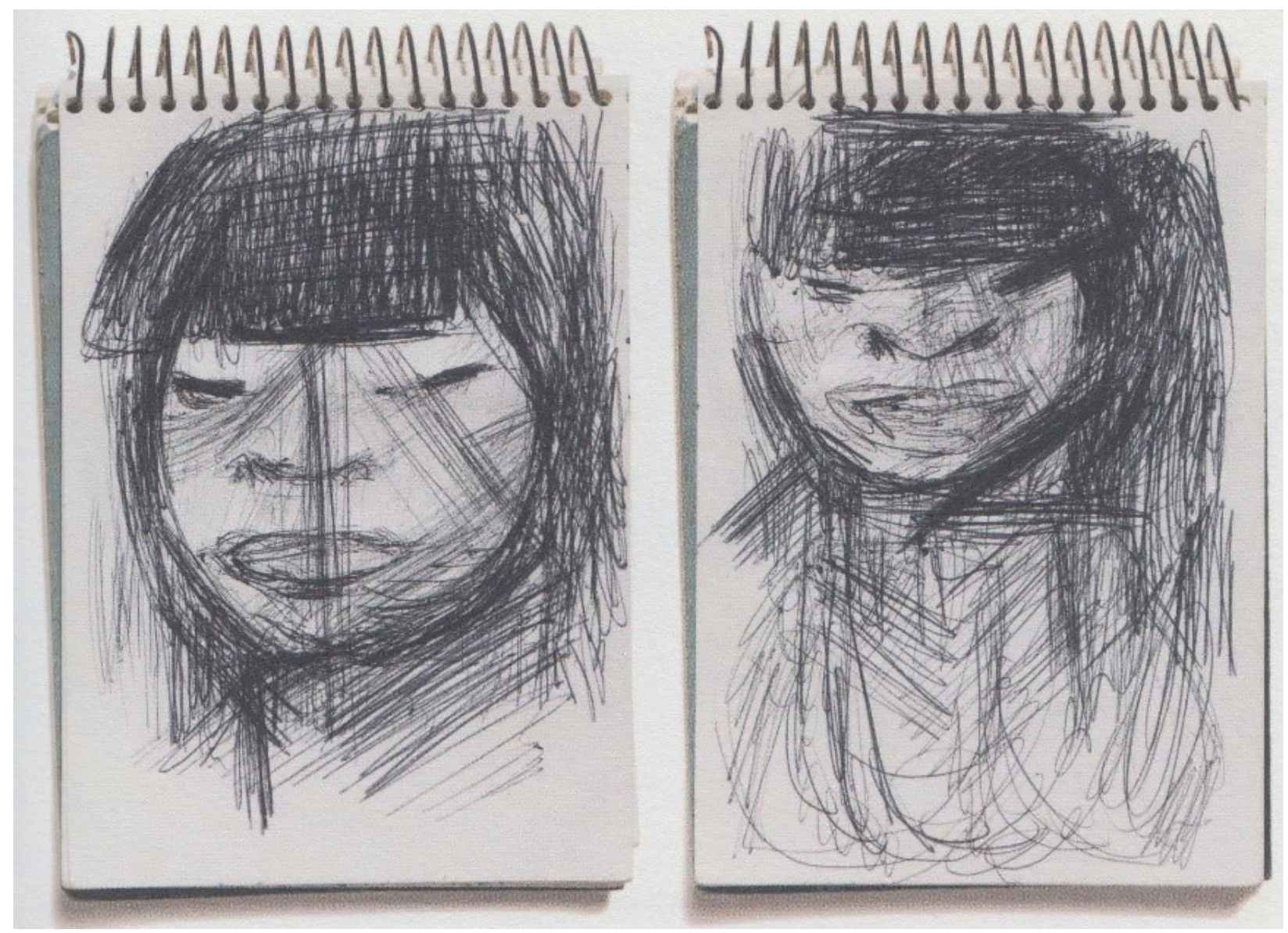

Figura 10 - Júlio Pomar, Desenhos de Rosto de Mulher, 1988. Esferográfica sobre papel, 2 páginas, $13 \times 9$ cm. Fonte: Pomar, 2017a.

- Nu, como tema, ao incorporar o movimento enquanto componente visual irredutível (DONDIS, 2007, p. 82) da observação, lembra os nus cubistas de Picasso, que romperam com o sistema Monge e com a projeção cónica tradicional.

O feminino foge à fixação hipnótica e erotizada dos nus de Velasquez, Ingres ou Manet, e aproximase da representação da mãe pela morfologia das Vénus do Paleolítico (Figuras 9 e 10). Enquanto que o masculino deixa a heroicidade grega clássica e exemplar (ANDRESEN, 2019, p. 30), para mostrar a forma social do corpo funcional e simbólico do homem, como nos desenhos do grupo indígena Txicão (Figura 11).

Esta pesquisa dos resíduos do movimento e do espaço, são em Pomar uma metodologia artística para compreender onde está a universalidade social. A função visual estruturante ensaiada nos desenhos do Xingu parece reforçar o conceito de 'modelo reduzido' (LÉVI-STRAUSS, 2008, p. 38), que Lévi-Strauss explica em $O$ Pensamento
Selvagem (1962), quando na produção da arte se transfere as dimensões sensíveis para as inteligíveis (LÉVI-STRAUSS, 2008, p. 40). Esta compressão visual, de escala e de perceção, é uma técnica de construção artística e ato mental de leitura do visível por um observador capaz dessa redução, e de a transferir para os meios e suportes da arte.

O 'modelo reduzido' é uma distinção entre estrutura e facto $^{9}$, e com isso o ato de desenhar "realiza a síntese das propriedades intrínsecas e das que dependem de um contexto espacial e temporal" (LÉVI-STRAUSS, 2008, p. 40-41), porque o "olhar tem uma economia própria" (POMAR, 2014, p. 218), como defende o próprio desenhador. Para além disso, acrescenta LéviStrauss: "a transposição gráfica ou plástica implica sempre uma renúncia a certas dimensões do objeto" (LÉVI-STRAUSS, 2008, p. 39). Uma experiência interpretativa que os desenhos de Pomar tornam acessíveis na manipulação da escala, e onde a inteligência visual da atenção 
do desenhador explica-se na redução da transferência gráfica:

uma espécie de inversão do processo de conhecimento: para conhecer o objeto real em sua totalidade, sempre tivemos tendência a proceder começando das partes. Dividindo-a, quebramos a resistência que ela nos opõe. A redução da escala inverte essa situação: quanto menor o objeto, menos temível parece a sua totalidade; por ser quantitativamente diminuído, ele nos parece qualitativamente simplificado. Mais exactamente, essa transposição quantitativa aumenta e diversifica nosso poder sobre um homólogo da coisa; através dela, este pode ser tomado, sopesado na mão, apreendido de uma só mirada (LÉVI-STRAUSS, 2008, p. 39).

A vantagem de apreensão em uma única olhada é a velocidade do gesto ocular e manual, que dissolve os parâmetros e as diferenças entre conjuntos, numa redução que a aproxima dos materiais e dos elementos da arte como artifício. Pelo 'modelo reduzido', a síntese visual torna a imagem acessível e direta, sem ser analítica. Um desenho gestual que contrasta com o mistério de Vermeer, a que Pomar, numa entrevista a Helena Vaz da Silva, faz referência: "O mistério de Vermeer é a criação de uma imagem que é tão afirmativamente real que dá a impressão que se ficar perante uma visão $(;)$ Tudo é quotidianamente exacto e transfigurado" (POMAR; SILVA, 1980, p. 42-44).

A velocidade e gestualidade do desenho unificam a geometria através da combinação dos ritmos visuais, com sugestões que desvendam o significado da estrutura de arranjos entre linhas e massas (SPEED, 1972, p. 131). A voracidade deste desenho gestual está implícita na coordenação entre os movimentos de presença e os tempos de interação compositiva, numa escala que vai do instante à assimilação panorâmica. Pedro Faro relaciona esta temporalidade com Barthes:

\begin{abstract}
Estes desenhos são «certificados de presença»usando a expressão de Barthes sobre os protocolos de verdade da fotografia -, valor que se torna por vezes mais importante do que a ideia ou trabalho de representação que daí advenha. A ideia de performance antecede cada desenho. Cada série de desenhos implica um tempo de interação, de relação e um trabalho de composição que não se limita ao instante, àquilo que fica e que sai, ao enquadramento (FARO, 2017, p. 195).
\end{abstract}

Se os desenhos gestuais do Xingu são essa caça da composição dos tempos, para mostrar não a diferença, mas asemelhança humana que ultrapassa

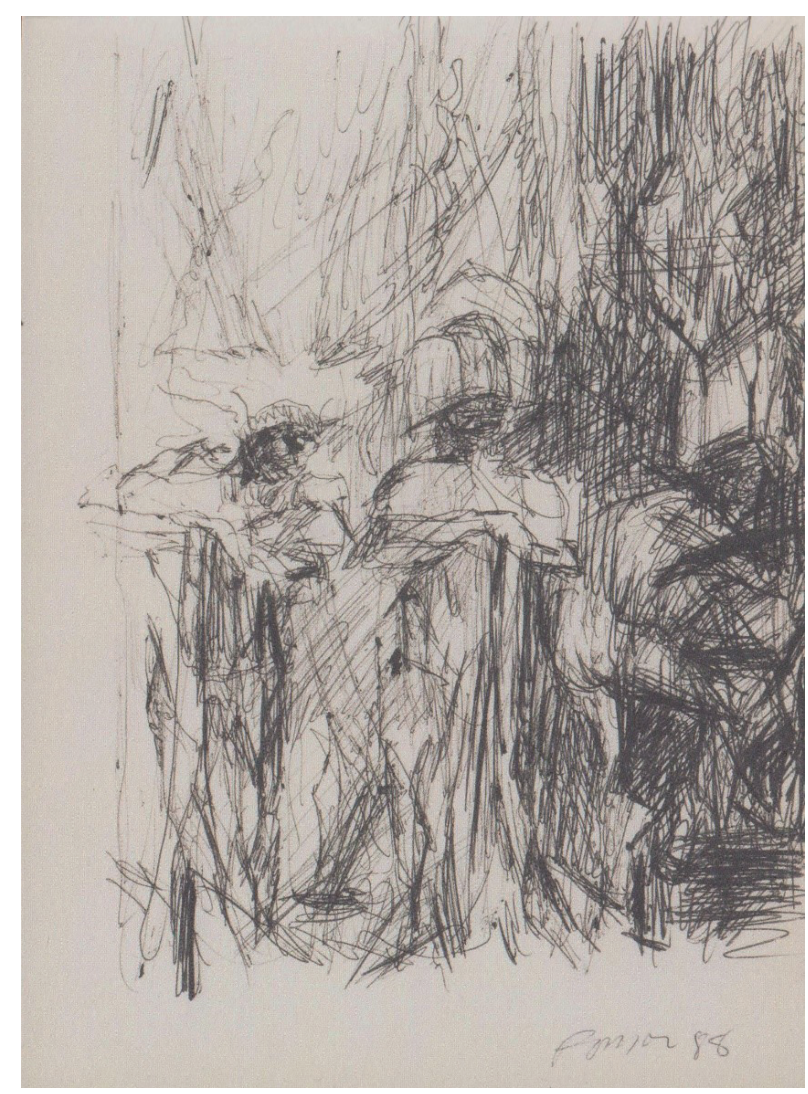

Figura 11 - Júlio Pomar, Desenho de Homens do Grupo Indígena Txicão, 1988. Esferográfica sobre papel, 21 x $15 \mathrm{~cm}$. Fonte: Pomar, 2017 .

a latitude, é em Platão, no Timeu, que encontramos o tempo como imagem móvel (da universalidade). Isto é, síntese para reduzir a entropia interna e a irreversibilidade ou desordem (PRIGOGINE, 2008, p. 35), entre os tempos de produção e os tempos de receção das formas, que nos remete para Deleuze em A Filosofia Critica de Kant (1963), onde a propósito do papel da imaginação explica que a "síntese é a determinação de um certo espaço e de um certo tempo, pela qual a diversidade é referida ao objecto em geral conformemente às categorias" (DELEUZE, 2017, p. 27)

A geometrização formal que tende para 0 abstracionismo em Pomar, é em si a tentativa para estar entre o essencial das representações temporais. Estas são, tal como o ser-simultâneo e o ser-sucessivo de Kant, acontecimentos anteriores á experiência, com funções que organizam a perceção visual intuitiva através da duração, como adverte Bergson .

Com o ser-simultâneo e o ser-sucessivo Kant elabora, na Crítica da Razão Pura (1781), um modelo de representação empírica do tempo 
como intuição sensível (KANT, 2001, p. 99-100), multivariável e por fluxo, em contraponto ao tempo como feixe, de Hume. Durante o desenhar, o observador materializa o tempo sucessivo entre registos sensoriais e marcas gráficas, mas utiliza um tempo simultâneo para construir relações e conjuntos (por exemplo, proporção, escala, composição, perspetiva, sombra), sem o qual fica comprometida a sucessão. Conceitos que acompanham a ideia de contentor ou temporalidade de Heidegger, em Ser e Tempo (1927), quando a propósito do paradoxo do presente, Pomar faz aparecer o desenho gestual ao eliminar os eixos antes-agora-depois:

Enquanto agora, todo último agora já é sempre um logo não mais. É, portanto, tempo no sentido de agora-não-mais, de passado; todo primeiro agora é sempre um há pouco, ainda-não e, com isso, tempo no sentido de agora-ainda-não, de futuro (HEIDEGGER, 2005, p. 236-237).

\section{NOTAS}

1. A pintura de Júlio Pomar teve várias fases, com variação de suportes e processos pictóricos, com elevado experimentalismo de materiais, formatos e composições. As formas alternaram entre o figurativo e o abstrato, com libertação da cor e do movimento, em planos lisos, fragmentos e ritmos geometrizantes. Nessa gestualidade e liberdade visual o artista visita vários temas: crítica social, retrato, animais, erotismo, história, literatura, mitologia. Trabalhou igualmente gravura, escultura, assemblage, cerâmica, tapeçaria e ilustração. 0 desenho, como fim em si mesmo, adquiriu um traço inconfundível e uma importância crucial na síntese gráfica do autor. Um estudo completo e abrangente sobre a obra de Pomar está compilado nos dois volumes do catálogo raisonné publicados pela La Différence: POMAR, Júlio. Catálogo "Raisonné" I - Pinturas, Ferros e "Assemblages" 19421968. Paris, Lisboa: Éditions de La Différence/ Artemágica, 2004 e POMAR, Júlio. Catálogo "Raisonné" II - Pinturas e "Assemblages" 19681985. Paris, Lisboa: Éditions de La Différence/ Artemágica, 2004.

2. O modernismo português teve várias expressões, e nas diferentes modalidades artísticas prolongou-se até à queda do Estado Novo. Teve como nomes de destaque Fernando
Pessoa, Almada Negreiros ou Pardal Monteiro. Como forma de acompanhar as vanguardas internacionais, num mundo em mudança e palco de duas guerras mundiais, as novidades artísticas em Portugal, acompanharam os combates sociais e políticos da modernidade, na urgência da velocidade e da técnica, com alteações nos temas, meios e processos de representação. O neorealismo na pintura portuguesa, a que Júlio Pomar está diretamente ligado por via da // Geração de Paris, foi um manifesto visual da denuncia social e a favor da liberdade de expressão, inspirado na reforma marxista. Ver FRANÇA, José Augusto. História da Arte em Portugal - O Modernismo. Lisboa: Editorial Presença, 2004.

3. Aqui primitivo não no sentido de arcaico, mas de primevo (do início dos tempos).

4. Kuarup (cor, 119 min.) é um filme de cariz político, realizado em 1989 por Ruy Guerra, e baseado no livro homónimo de Antônio Callado. Ver CALLADO, Antônio. Quarup. Lisboa: Publicações Europa-América, 1973. No filme a personagem de um missionário afasta-se do sacerdócio, e defende os povos indígenas contra a Ditadura Militar Brasileira de 1964.

5. O desenho etnográfico é uma prática de observação e registo da cultura dos povos. Em termos históricos esteve ligado à visão colonial do exotismo dos autóctones, mas tem evoluído para estudos sobre relações, comportamentos, técnicas, saberes e experiências no contexto da antropologia visual. 0 desenho da cultura material, da paisagem, dos ritos e do quotidiano têm servido de temas para conhecer o objeto de estudo. Para cruzamentos entre estas áreas de conhecimento ver o dossier "Antropologia e Desenho" (2016) dos Cadernos de Arte e Antropologia do Departamento de Antropologia e Etnologia da Faculdade de Filosofia e Ciências Humanas, da Universidade Federal da Bahia (Salvador, Brasil). Nomeadamente o artigo KUSCHNIR, Karina. A antropologia pelo desenho: experiências visuais e etnográficas. Cadernos de Arte e Antropologia, vol. 5, n. 2, 2016, p. 5-13.

6. 0 desenho de reportagem está associado a uma narrativa jornalística ou a conteúdo informativo. Em Pomar, os desenhos não são tratados como se fossem conjuntos de notícias. 
7. Exposição realizada no Atelier-Museu Júlio Pomar, entre os finais de outubro de 2017 e inícios de fevereiro de 2018, com curadoria de Alexandre Melo, e integrada no programa Passado e Presente - Lisboa, Capital Ibero-Americana da Cultura 2017.

8. A primeira edição portuguesa é de 1986.

9. A distinção entre estes dois conceitos é fundamental para a teoria de 'modelo reduzido': "Nós diferenciamos o cientista e o bricoleur pelas funções inversas que, na ordem instrumental e final, eles atribuem ao fato e à estrutura, um criando fatos (mudar o mundo) através de estruturas, o outro criando estruturas através de fatos" (LÉVI-STRAUSS, 2008, p. 38).

10. Sobre a relação das categorias temporais entre Bergson e Kant ver MASCARENHAS, Aristeu L. C. Bergson e Kant: O Problema do Tempo e os Limites da Intuição. Trans/Form/Ação, vol. 4, n. 2, Abril/ Junho 2017, p. 103-124.

\section{REFERÊNCIAS}

ANDRESEN, Sophia de Mello Breyner. O Nu na Antiguidade Clássica | Antologia de Poemas sobre a Grécia e Roma. Porto: Assírio \& Alvim, 2019.

ARNHEIM, Rudolf. O Poder do Centro. Lisboa: Edições 70, 2001.

BÔAS, Orlando Villas; BÔAS, Cláudio Villas. A Marcha para o Oeste: a epopeia da Expedição Roncador-Xingu. São Paulo: Companhia das Letras, 2012.

BRAUNSTEIN, Florence; PÉPIN, Jean-François. O Lugar do Corpo na Cultura Ocidental. Lisboa: Instituto Piaget, 2001.

CAPELATO, Maria Helena. O Estado Novo: o que trouxe de novo?. In: FERREIRA, Jorge; DELGADO, Lucilia de Almeida Neves (orgs.). O Brasil Republicano - o tempo do nacional-estatismo: do início da década de 30 ao apogeu do Estado Novo. Volume 2. Rio de Janeiro: Civilização Brasileira, 2017, p. 109-140.

COSTA, Maria Heloísa Fénelon; MALHANO, Hamilton Botelho. Habitação Indígena Brasileira. In: RIBEIRO, Berta G. (coord.); RIBEIRO, Darcy (ed.) et al. Suma Etnológica Brasileira, Volume
2 Tecnologia Indígena. Rio de Janeiro: Vozes, 1986, p. 27-94.

DELeUZE, Gilles. A Filosofia Crítica de Kant. Lisboa: Edições 70. 2017.

DONDIS, Donis A. Sintaxe da Linguagem Visual. São Paulo: Martins Fontes, 2007.

EMBURY, Gary; MINICHIELLO, Mario. Reportagem ilustrada, Do desenho ao jornalismo: princípios básicos, técnicas e recursos. São Paulo: Gustavo Gilli, 2018.

FARO, Pedro. Pomar - Antes, Durante e Depois da Amazónia. A esferográfica, o marcador, o lápis e a tinta. In: ESILVA, Dealmeida; JESUS, Igor; ALEXANDRE, Tiago; POMAR, Júlio. Táwapayêra. Lisboa: Atelier-Museu Júlio Pomar/ Documenta, 2017, p. 189-200.

FILHO, Orlando Villas Bôas (org.). Expedições, Reflexões e Registos. São Paulo: Metalivros, 2006.

FREITAS, Fábio de Oliveira; FREITAS, Joana Zelma Figueredo. Relato sobre Mudança Cultural em Comunidades do Parque Indígena do Xingu. Brasília: Embrapa - Recursos Genéticos e Biotecnologia, 2003.

GHeERBRAnT, Alain. Júlio Pomar - Peinture et Amazonie. Paris: La Différence, 1997.

GONÇALVES, Ana. Táwapayêra. Dossier Educativo Nº06. Lisboa: Atelier-Museu Júlio Pomar, 2017.

HEIDEGGER, Martin. Ser e Tempo. Parte II. Rio de Janeiro: Editora Vozes, 2005.

KANT, Immanuel. Crítica da Razão Pura. Lisboa: Fundação Calouste Gulbenkian, 2001.

LÉVI-STRAUSS, Claude. O Pensamento Selvagem. Campinas, São Paulo: Papirus Editora, 2008.

LIBBY, Lisa K.; SCHAEFFER, Eric M.; EIBACH, Richard $P$. Seeing Meaning in Action: A Bidirectional Link Between Visual Perspective and Action Identification Level. Journal of Experimental Psychology: General, vol. 138, n. 4, 2009, p. 503-516.

MATOS, Sara Antónia. À Partida e À Chegada: A Pintura de Pomar e a Festa Táwapayêra. In: ESILVA, Dealmeida; JESUS, Igor; ALEXANDRE, Tiago; POMAR, Júlio. Táwapayêra. Lisboa: Atelier-Museu Júlio Pomar/ Documenta, 2017, p. 21-27. 
MOREIRA, Júlio. Impulso e Estrutura na Obra de Júlio Pomar. In: BASILIO, Kelly Benoudis (coord.). Júlio Pomar, 0 "Jogo da Cabra Sábia". V. N. Famalicão: Edições Húmus, 2019, p. 71-86.

PANOFSKY, Erwin. A Perspectiva Como Forma Simbólica. Lisboa: Edições 70, 1993.

POMAR, Júlio. Duas «Cenas de Banhistas». Em Post Scriptum. In: ESILVA, Dealmeida; JESUS, Igor; ALEXANDRE, Tiago; POMAR, Júlio. Táwapayêra. Lisboa: Atelier-Museu Júlio Pomar/ Documenta, 2017a, p. 101-102.

POMAR, Júlio. Kuarup. In: ESILVA, Dealmeida; JESUS, Igor; ALEXANDRE, Tiago; POMAR, Júlio. Táwapayêra. Lisboa: Atelier-Museu Júlio Pomar/ Documenta, 2017a, p. 109-111.

POMAR, Júlio. Temas e Variações, Parte Escrita III 1968-2013. Lisboa: Atelier-Museu Júlio Pomar/Documenta, 2014.

POMAR, Júlio. Xingu. Lisboa: Fundação Júlio Pomar, 2017b.

POMAR, Júlio; SILVA, Helena Vaz da. Helena Vaz da Silva com Júlio Pomar. Lisboa: Edições António Ramos, 1980.

PRIGOGINE, Ilya. O Nascimento do Tempo. Lisboa: Edições 70. 2008.

RANCIÈRE, Jacques. A partilha do sensível: estética e política. São Paulo: Editora 34, 2005.

ROSENDO, Catarina. Escritos de Artista em Portugal: história de um esquecimento. Lisboa: Documenta, 2016.

SPEED, Harold. The Practice \& Science of Drawing. Nova Iorque: Dover Publications Inc., 1972.

WOHL, Hellmut. Júlio Pomar: A Comédia Humana. In: WOHL, Hellmut; TABUCCHI, Antonio; SEIXAS, Maria João. Júlio Pomar: A Comédia Humana. Lisboa: Fundação Centro Cultural de Belém, 2004, p. 8-37.

\section{SOBRE O AUTOR}

Shakil Y. Rahimé Arquiteto e Doutor em Arquitetura, especialidade Desenho, pela Faculdade de Arquitetura da Universidade de Lisboa. É Professor de Desenho e Desenho Arquitetónico na Universidade de Lisboa, Departamento de Desenho, Geometria e Computação. Pertence ao CIAUD e as suas áreas de estudo são: desenhador, desenho, atenção visual, inteligência espacial, experiência do gesto, cognição humana. E-mail: rahim.shakil@gmail.com 